\title{
Using Ecosystem Service Bundles to Evaluate Spatial and Tmporal Impacts of Large-scale Landscape Restoration on Ecosystem Services on the Chinese Loess Plateau
}

\section{Hao Chen ( $\nabla$ hao.chen@wur.nl)}

Wageningen UR: Wageningen University \&amp; Research https://orcid.org/0000-0002-5662-1194

Luuk Fleskens

Wageningen University \&amp; Research

Johanna Schild

Wageningen University \&amp; Research

Simon Moolenaar

Commonland Foundation

\section{Fei Wang}

Institute of Soil and Water Conservation Northwest A \&amp; F University: Institute of Soil and Water Conservation Chinese Academy of Sciences and Ministry of Water Resources

\section{Coen Ritsema}

Wageningen University \&amp; Research

\section{Research Article}

Keywords: land restoration, InVEST model, trade-offs and synergies, ecosystem service bundles

Posted Date: April 9th, 2021

DOI: https://doi.org/10.21203/rs.3.rs-273669/v1

License: (9) This work is licensed under a Creative Commons Attribution 4.0 International License. Read Full License 
1 Using ecosystem service bundles to evaluate spatial and temporal impacts of

2 large-scale landscape restoration on ecosystem services on the Chinese Loess

\section{Plateau}

4 Hao Chen ${ }^{*}$, Luuk Fleskens a, Johanna Schild a, Simon Moolenaar c, Fei Wang b and Coen Ritsema a

5 a Soil Physics and Land Management, Wageningen University, P.O. Box 47, 6700 AA Wageningen, The

$6 \quad$ Netherlands

7 b Institute of Soil and Water Conservation, Chinese Academy of Sciences and Ministry of Water Resources,

8712100 Yangling, China

9 c Commonland Foundation, Kraanspoor 26, 1033 SE Amsterdam, the Netherlands

10 * Correspondence: hao.chen9527@outlook.com 


\section{Abstract}

13 Context

14 From 1999 onwards, China has initiated a large-scale landscape restoration project on the Chinese 15 Loess Plateau, which has had profound but variable impacts on the local ecosystem services supply.

16 There was less understood of land restoration impacts on the ecosystem services and dynamics of 17 ecosystem services thoroughout the restoration process.

18 Objectives

19 To to analyse the spatial and temporal dynamics in ecosystem services before and after the 20 implementation of the land restoration project, and to understand trade-offs and synergies between 21 multiple ecosystem services.

22 Methods

23 We used InVEST model and statistical yearbook data to quantify the ecosystem, the concept of 24 ecosystem service bundles was applied to understand the dynamics of ecosystem services.

25 Results

26 A significant increase of fruit production, sediment retention, habitat quality, aesthetic landscape 27 value, learning and inspiration value was found overtime in Yan'an area, while a decrease of timber production and water yield was also observed. The majority of ecosystem services bundles area were transformed from having a focus on timber production to aesthetic landscape value. The dynamics of ecosystem services change by land restoration was discovered, to start with increasing regulating

31 services at expense of provisioning services, cultural services exceeding regulating services and occupied the main proportion subsequently.

33 Conclusion

34 Both trade-offs and synergies were found between provisioning, regulating and cultural services, 35 implementation of the large-scale restoration project is recognized as a key driving force inducing 36 change of ecosystem services.

37 Keywords: land restoration, InVEST model, trade-offs and synergies, ecosystem service bundles. 


\section{Introduction}

Over $40 \%$ of the world's land surface are arid and semi-arid areas, which are ecologically vulnerable, sensitive to erosion and facing deterioration risks (Allan et al. 2013). In order to manage and address land degradation and ecological deterioration issues, a number of large-scale land restoration programs have been implemented worldwide, which have significantly altered land use and ecosystem services (Benayas et al. 2009). China is no exception: especially the Chinese Loess Plateau, one of the most severely eroded regions in the world, has been given a lot of attention in land restoration policies (Sun et al. 2014). Starting from the 1970s, the Chinese government has implemented several small-scale land restoration programs on the Chinese Loess Plateau to rehabilitate vegetation cover, combat desertification and reduce soil and water loss (Chen et al. 2015). In 1998, Wuqi county in Yan'an area on the Chinese Loess Plateau started a pioneer land restoration program to reverse the ecological degradation by stopping cultivation of steep slopes and converting cropland and bare land to forest and grassland. One year later, based on the experiences in 1999, one of the world's largest-scale land restoration projects, the Grain for Green project (GGP), was initiated nationally covering more than 20 million hectares of cropland and bare land (Persson et al. 2013). One of the main purposes of the GGP is to maintain soil fertility and combat soil and water losses (Deng et al. 2019). GGP brought a dramatic alteration of land use and a transformation in ecosystem services delivery (Chen et al. 2015).

Ecosystem services are defined as flows of materials, energy and information which are directly or indirectly provided by ecosystems to human society, including provisioning, regulating, cultural and supporting services (Costanza et al. 1997). Provisioning services include goods and products that we physically obtain from ecosystems, for example, food, water, raw materials etc; Regulating services are necessary services to maintain the ecosystem functions, for instance, erosion control, sediment retention, habitat quality etc; Cutural services like aesthetic landscape value provide spiritual pleasures to human beings (MEA 2005). Multiple ecosystem services can be provided by an ecosystem at the same time, but some ecosystem services cannot be supplied to society simultaneously (Peng et al. 2019). Any of these ecosystem services is associated with other services as either "trade-offs" or "synergies" (Bennett and Balvanera 2007). Trade-offs between ecosystem 
services can be comprehended as an increase of a (set of) specific ecosystem service(s) at the expense of other ecosystem services (Raudsepp-Hearne et al. 2010). Synergies, which are the opposite to tradeoffs, are characterized as ecosystem services that either increase or decrease jointly (Bennett et al. 2009). Meanwhile trade-offs and synergies may appear diversely in one ecosystem at different temporal and spatial scales (Power 2010). Understanding the dynamics of ecosystem services is thus essential to comprehend the possible formation of trade-offs and synergies (Dade et al. 2019). Ignoring dynamics may increase the risk of unexpected changes in ecosystem services (Gordon et al. 2008). Human activity is a major factor affecting ecosystem service trade-offs and synergies through changing land use , by scale, type and intensity (Tolessa et al. 2017; Chen et al. 2019). For example, urbanization, ecological engineering and landscape restoration are often accompanied by a shift in land use for the purpose of (re-)generating a single or multiple ecosystem services. The implementation of these land use changing activities could cause ecological degradation if the tradeoffs among other ecosystem services are ignored (Groot et al. 2011). Many previous studies were focused on simple trade-off and synergy relations between ecosystem services and ignore exploration of drivers and mechanisms. The application of the ecosystem services bundles concept is helpful to understand the provisioning mechanisms of ES and the dynamics among multiple ecosystem services. Ecosystem service bundles are defined as a mix of correlated ES provided at the same location and at the same time, though they may not have any direct causal relationships (Renard et al. 2015).

Impacts of the GGP on trade-offs and synergies between multiple ecosystem services has been investigated in multiple scientific studies. Many previous studies have analyzed ecosystem services supply on the Chinese Loess Plateau, and several address the dynamics and relations between different ecosystem services. For example, Lü et al. (2012) discovered that the entire Chinese Loess Plateau was transformed from a carbon source to a carbon sink by mapping carbon sequestration dynamics from 2000 to 2008. Feng et al. (2017) found out that vegetation coverage and types are the main factors that affect soil erosion control, soil moisture conservation and carbon sequestration based on field experiments in 2014. However, the majority of previous studies mainly put emphasis on single trade-off and synergy relations between regulating services, such as soil retention, water 
retention and water purification, ignoring the changes of other ecosystem services and the driving forces behind such changes. Meanwhile, some researchers focus on comparing ecosystem services after a certain time period against a baseline, but neglect the dynamics during that time span (Y. Liu et al. 2019). For example, Li et al. (2019) mapped changes of ecosystem services in the entire Loess Plateau from year 2000 to 2015, without describing the fluctuation of ecosystem services within these 15 years. Besides, cultural services, which are defined as the nonmaterial benefits people obtained from the ecosystem, was not taken into account in the studies on the Loess Plateau. Furthermore, due to vegetation growth and continuance of GGP, there is a lack of research considering the most recent impacts of GGP on the ecosystem services on the Loess Plateau. Thus, in order to monitor the dynamic impacts of the GGP across various categories of ecosystem services, we considered the time period 1990-2018 (including before and implementing phases of the GGP project) and selected 11 ecosystem services covering four provisioning, four regulating and three cultural services.

The implementation of the GGP is expected to have affected a range of ecosystem services on the Loess Plateau. GGP proposed a reduction in cultivated area in return for an increase in forest and grassland area. Provisioning services, such as grain, livestock, fruit and timber were assessed in order to quantify the impacts from GGP land restoration measures. The main goal of the GGP is to prevent soil and water loss and maintain soil quality, thus, we included sediment retention and carbon sequestration as ecosystem indicators in our analysis. Additionally, it has been found that land restoration plays an important role in the reduction of surface streamflow on the Chinese Loess Plateau (Chen et al. 2020). Therefore, seasonal water yield, as an indicator for water supply, was also considered in this study. Furthermore, a primary goal of restoration is the protection of biodiversity, including genes, species, populations, habitats and ecosystems (Hector and Bagchi 2007), therefore, habitat quality is also quantified. Here, we define habitat as "the resources and conditions present in an area that produce occupancy - including survival and reproduction - by a given organism" (Hall et al. 1997, p. 175). Cultural services, like all other ecosystem services, must demonstrate unique relations between ecosystem structures and meeting the satisfaction of human needs (Daniel et al. 2012 ). Cultural services, including outdoor recreation, aesthetic value of the landscape and learning and inspiration values were considered. 
122 The main objectives of this study are a) to analyse the spatial and temporal dynamics in ecosystem

123 services before and after the implementation of the GGP using ecosystem service bundles; and b) to 124 understand trade-offs and synergies between multiple ecosystem services.

\section{2. Methods}

\section{$126 \quad 2.1$ Study area}

127 The study area of Yan'an is located in the northern Shaanxi province on the south-central part of the

128 Chinese Loess Plateau at latitude $35^{\circ} 21^{\prime}-37^{\circ} 31^{\prime} \mathrm{N}$ and longitude $107^{\circ} 41^{\prime}-110^{\circ} 31^{\prime}$ E. Yan'an is a 129 prefectural-level municipality covering an area of $37,030 \mathrm{~km}^{2}$. It is a typical hilly area on the Loess 130 Plateau that consist of multiple deeply incised valleys. The main soil type is Calcareous Cinnamon Soil 131 (Xu et al. 2020). The terrain of Yan'an is higher in the northwest (highest point: $1795 \mathrm{~m}$ ) and lower in 132 the south east (lowest point: $353 \mathrm{~m}$ ), having an average elevation of around $1200 \mathrm{~m}$ (Fig. 1). Yan'an 133 belongs to a semi-humid, warm temperate climate zone with continental monsoon circulation. The 134 average annual temperature is $9.9^{\circ} \mathrm{C}$ and annual precipitation is $510.7 \mathrm{~mm}$. In 1998, Yan'an area was 135 selected as the first experimental site to start the GGP land restoration project in its northwestern 136 Wuqi county. Up to now, Yan'an has implemented vegetation restoration for nearly 20 years and restored around $7200 \mathrm{~km}^{2}$ of degraded land (Guo and Gong 2016).

\subsection{Data sources}

139 Land use and land cover (LULC) data of Yan'an area at a $30 \mathrm{~m}$ resolution for the years 1990, 1995, 140 2000, 2005, 2010, 2015 and 2018 was provided by the Data Center for Resources and Environmental

141 Sciences of the Chinese Academy of Science (http://www.resdc.cn). This data was extracted from 142 remote sensing data of Landsat-TM/ETM and Landsat 8. LULC data was classified into six classes: 143 cropland, forest, grassland, water body, urban land and bare land (Fig. 2). Meteorological data from 144 1990-2018, including precipitation, solar radiation, temperature, humidity and evapotranspiration, 145 was obtained from the National Meteorological Administration of China (http://data.cma.cn) for 146 meteorological stations (see Fig. 1). A 30 m resolution DEM of Yan'an was obtained from the ASTER 147 Global Digital Elevation Model (ASTER GDEM) from the Geospatial Data Cloud site of the Computer 148 Network Center of the Chinese Academy of Science (http://www.gscloud.com). A soil erodibility 
map of Shaanxi province was obtained from the National Earth System Science Data Center

150 (http://geodata.cn) and a world rainfall erosivity index map was acquired from the European Soil

151 Data Center (ESDAC); http://esdac.jr.ec.europa.eu). Additionally, world soil group data was 152 provided by EARTHDATA from NASA (http://earthdata.nasa.gov). Statistical data of the 13 counties 153 in Yan'an was derived from the Statistical Yearbook of Yan'an from the Yan'an Statistical Bureau

154 (http://tij.yanan.gov.cn/).

\subsection{Quantification of ecosystem services}

156 Eleven ecosystem services were selected to monitor the impacts of the GGP land restoration project in the 13 counties of Yan'an area (Table 1). Each ES was quantified in a biophysical way for the 13

158 individual counties of Yan'an area over a time period of 28 years split into 7 time intervals from 1990 159 up to 2018.

160 Indicators for the four provisioning services were derived from the statistical yearbook. As an 161 indicator for grain production, the average yield of wheat and corn of each county (in $\left.\mathrm{t} / \mathrm{km}^{2}\right)$ was used. Apple yield $\left(\mathrm{t} / \mathrm{km}^{2}\right)$ was used as an indicator for fruit production. Livestock production was

163 indicated by pork, beef and mutton meat productivity $\left(\mathrm{t} / \mathrm{km}^{2}\right)$. Timber production was indicated by 164 the weight of timber produced per hectare $\left(\mathrm{t} / \mathrm{km}^{2}\right)$. Four regulating services, including carbon sequestration $(\mathrm{Mg} / \mathrm{ha})$, sediment retention $(\mathrm{t} / \mathrm{ha})$, seasonal water yield ( $\mathrm{mm}$ of base flow) and habitat

166 quality (index from 0-1), were assessed by the Integrated Valuation of Ecosystem Services and Trade167 offs (InVEST) model (Nelson et al. 2018), which is explained in detail in sections 2.3.1-2.3.4. Indicators 168 for the three cultural services were obtained from the statistical yearbook and the LULC map, 169 respectively. Terrace area (\%) was used as an indicator for the aesthetic value of the landscape, forest 170 area (\%) offered an underpinning for outdoor recreation and the number of local cultural institutes $171\left(\mathrm{n} / 1000 \mathrm{~km}^{2}\right)$ for entertainment and cultural education as an indicator for learning and inspiration.

172 Additionally, the gross value of agriculture, industry and forestry (in USD $/ \mathrm{km}^{2}$ ) as well as population 173 density (in person $/ \mathrm{km}^{2}$ ) were calculated from the statistical yearbook as covariables.

\section{$174 \quad$ 2.3.1 Carbon sequestration}


175 Carbon sequestration (CAS) was calculated based on the carbon storage and sequestration model

176 from InVEST (version 3.7.0). This model is composed of three parts to calculate the carbon storage

177 (eq. 1): 1) carbon from plants including aboveground biomass and belowground biomass; 2) carbon

178 from soil; 3) carbon from dead litter. Based on this calculation, land use and land cover change

179 contribute mostly to changes in carbon storage due to changes in vegetation types.

$$
C_{\text {carbon }}=C_{\text {above }}+C_{\text {below }}+C_{\text {soil }}+C_{\text {dead }}
$$

180 To run this model, land use maps and carbon pools which indicate carbon storage values of different

181 land use types are required. In this study, carbon sink data is based on experimental field data

182 collected in Yan'an area: aboveground biomass data was obtained from Xiao et al. (2016),

183 belowground biomass from Feng et al. (2017), soil carbon content from Zhang et al. (2019) and dead

184 litter from Zhang et al. (2001).

\subsubsection{Seasonal water yield}

Because Yan'an has a typical seasonal climate where precipitation is usually concentrated between

187 July and September (Yang et al. 2018), the seasonal water yield model from InVEST was used to estimate water yield of the 13 counties in Yan'an. This model represents seasonal water yield (SWY) using two indices: quick flow and base flow. Quick flow indicates the generation of streamflow of hours to days, whereas base flow is defined as the generation of streamflow of months to years

191 (Nelson et al. 2018). In order to monitor yearly water yield and reducing the climate variability impacts from fluctuating precipitations, base flow (in $\mathrm{mm}$ ) was used while quick flow was excluded 193 in this study.

194 The SWY model requires a series of monthly evapotranspiration (ET1-ET12) maps, monthly precipitation ( $\left.\mathrm{P}_{1-\mathrm{P}_{12}}\right)$ maps, DEM, LULC maps, soil groups and integer Curve Numbers $(\mathrm{CN})$. Monthly evapotranspiration was calculated with the R-package evapotranspiration (version 3.6.2) using meteorological data. Raster maps for monthly evapotranspiration and precipitation were created using the kriging tool in ArcGIS (version 10.5), based on the locations of the meteorological 
Engineering Handbook of United States Department of Agricultural

201 (https://directives.sc.egov.usda.gov/17758.wba).

\subsubsection{Sediment retention}

203 Sediment retention (SDR) in Yan'an area was calculated using the sediment delivery ratio model from

204 InVEST. This model is a spatially explicit model based on the spatial resolution of the input DEM 205 raster map. The calculation of the sediment delivery ratio consists of two parts (Nelson et al. 2018).

206 The first part computes the annual soil loss from each pixel in the raster map based on the Revised 207 Universal Soil Loss Equation model (RUSLE; Renard 1997). The second part generates the portion of 208 soil loss that eventually reaches the stream and accounted for the final water yield results (Bhattarai 209 and Dutta 2007), the RUSEL model is explained as below:

$$
u_{s l e_{i}}=R_{i} * K_{i} * L S_{i} * C_{i} * P_{i}
$$

210 where $u s l e_{i}$ is the amount of annual soil loss in one pixel, $R_{i}$ is the rainfall erosivity which is derived 211 from the world erosivity map, $K_{i}$ is derived from the soil erodibility map, $L S_{i}$ is the length-gradient 212 factor (calculated from the DEM), and $C_{i}$ and $P_{i}$ are the crop management and support practice 213 factors, respectively, which were obtained from Fu et al. (2005).

\subsubsection{Habitat quality}

215 Habitat quality $(\mathrm{HBQ})$ was quantified using the InVEST habitat quality model. This model combines 216 information from the LULC map and disturbances to biodiversity to generate a habitat quality map 217 (on an indexed scale between 0-1, 1 indicates a perfect habitat to live). Both the impacts from 218 biodiversity disturbances and the distance between the habitat and the threat sources are considered 219 in the model. Biodiversity disturbances of both negative and positive induced sources were 220 accounted, negative sources include mining areas, roads, railways, urban areas and other populated 221 areas, positive sources contain natural reserves and national parks. The dynamics in biodiversity 222 threats over the 1990-2018 time period were presented by threats maps that varied over time. The 223 location of the threats' maps were obtained from the Worldmap dataset of Harvard University 


\subsection{Statistical methods}

226 Based on the above models and statistical data, we quantified 11 ES, including four provisioning 227 services, three regulating services and four cultural services. In order to understand the spatial and 228 temporal dynamics of each ES, we used the Space-Time Interaction (STI) method from Legendre, 229 Cáceres, and Borcard (2010). This method tests space-time interactions in repeated ecological data, 230 where there are no replications at the level of individual sampling units. In STI, variables of time and 231 space were coded by principle coordinates of neighbor matrices into a two-way analysis of variance 232 (ANOVA) model (Renard et al. 2015). A significant result of STI $(\mathrm{p}<0.01)$ indicates that the spatial 233 distribution of an ES has changed over time. In our study, STI was processed using the package 234 adespatial in R (version 3.6.3), setting each STI test at 999 permutations. Each ES was calculated based 235 on its mean \pm SD across all 13 counties and taking the average value based on county area. Synergies and trade-offs between various ecosystem services were analyzed using Pearson correlation analysis 237 in R (version 3.6.1). For every research year, the average value of each ecosystem service was defined 238 at county level and each ecosystem service was standardized to a comparable unit scale from -1 to 1.

239 Correlations between different ES were determined for the study period 1990 to 2018 . Ecosystem 240 service bundles were subsequently defined to assess the dynamics of multiple ecosystem services 241 jointly. Ecosystem service bundles were analyzed using k-means cluster analysis from the package 242 cluster in R (version 3.6.3). Maps with ecosystem service bundles were visualized using ArcGIS 243 (version 10.5). Additionally, in order to understand the dominant patterns of ecosystem services 244 values among different temporal and spatial scales, principle component analysis (PCA) was applied 245 through R package ggplot (Wold et al. 1987).

\section{$246 \quad 3 . \quad$ Results}

\subsection{Spatial and temporal dynamics in ecosystem services}

248 In Figure 2, the spatial and temporal dynamics of the 11 ES are presented that resulted from the STI 249 analysis. For provisioning services, an obvious increase in fruit production was observed from 2005 250 to 2015. Results from the STI analysis $(\mathrm{p}<0.001)$ indicate that this increase only happened in a few 251 specific counties. Livestock production almost doubled from 1990 to 2018 and this increase occurred 
across all counties. Grain production fluctuated in all counties during the research period. A drop in grain production was observed in 2000, followed by an increase. In contrast, timber production showed a clear drop starting from 1995 up until 2005. During this time period, timber production decreased with almost $80 \%$. After 2005, the production level tended to stabilize.

For regulating services, a gradual increase was generally observed in sediment retention, carbon sequestration and habitat quality. This gradual increase was not covering all counties, but took place in several specific counties (see Figure. A1-A3); a significant $\mathrm{p}<0.001^{*}$ from STI test results was found for three regulating services (CAS, SDR and HBQ). Meanwhile the highest increase was determined in 2005 in both regulating services CAS and HBQ. Trends for water yield were fluctuating. Water yield dropped in 1995 and increased again in 2010 and 2018. These fluctuations in seasonal water yield occurred in all counties from 1990 to 2018 as was illustrated by the STI test results ( $\mathrm{p}$ value $=$ 0.052; see Figure. A4).

Cultural services, such as habitat quality and outdoor recreation, showed similar increasing trends as the three regulating services. The values for outdoor recreation, aesthetic landscape value, and learning and inspiration all increased from 1990 to 2018. Results from the STI test ( $\mathrm{p}$ value $<0.001^{*}$ ) indicate that changes in outdoor recreation and aesthetic value of the landscape only occurred in specific counties of Yan'an area (see Figure. A5 for outdoor recreation), while learning and inspiration improved in all 13 counties. Overall, the spatial and temporal dynamics of the 11 ecosystem services indicated that the majority of the selected services showed an increasing trend. Only trends for timber production decreased clearly, while water yield decreased from 1990 to 1995 and increased after 2005 onwards.

\subsubsection{Trade-offs and synergies between ecosystem services}

In the trade-offs and synergies analysis of the ecosystem services, we found that the majority of ecosystem services showed synergistic relations. We used the average value of 11 ecosystem services in each research year at county scale. In Figure 3, linear correlations between all ecosystem services are displayed, ordered by size of the Pearson correlation coefficient $(r)$. Positive correlations indicate a synergy between services $(0<r<1$; displayed in blue color in Fig. 3$)$, while negative correlations 
indicate a trade-off between services $(-1<r<0$; displayed in red color in Fig. 3). In general, the figure

280 shows that the majority of the correlations are positive, indicating synergies between those ecosystem 281 services. For instance, there are strong synergies between aesthetic landscape value, learning and inspiration, livestock production, carbon sequestration, outdoor recreation, fruit production, 283 sediment retention and habitat quality.

284 For provisioning services, fruit production showed a strong synergy with the majority of other 285 ecosystem services, except for a trade-off with timber production. Also, livestock production had a 286 trade-off with timber production. Timber production had trade-offs with the majority of the other 287 services, except for a synergy with grain production. Grain production showed no significant 288 correlation with majority of other services, besides a slight synergy with timber production. 289 Regulating services, including carbon sequestration, habitat quality and sediment retention had synergies between each other. Water yield showed trade-off correlations with the aesthetic landscape 291 value and livestock production. As for cultural services, outdoor recreation showed synergies with 292 the majority of the regulating services, while trade-offs with provisioning services were observed. 293 Learning and inspiration and aesthetic landscape value had similar correlations with other ecosystem 294 services. Additionally, the aesthetic value of the landscape had trade-offs with water yield and timber 295 production, while learning and inspiration only showed a significant trade-off with timber 296 production. The highest synergy was found between carbon sequestration and outdoor recreation $(r$ $=0.99)$, and between sediment retention and habitat quality $(r=0.98)$. Additionally, carbon 298 sequestration showed very strong synergies with sediment retention and habitat quality $(r=0.98$ and $299 r=0.97$, respectively). Highest trade-offs were found between timber production and outdoor recreation $(r=-0.89)$, followed by timber production and carbon sequestration $(r=-0.85)$.

\subsubsection{Principle component analysis between ecosystem services}

302 By a combined analysis of a PCA and the Pearson correlations, the internal structure and explained 303 variance of the trade-offs and synergies between different ecosystem services was investigated. The 304 result of the PCA can be found in Figure 4 component 1 (PC1) explained 70.1\% of the total variance while component 2 (PC2) explained 11.4\%, apparently the summed variance of PC1 and PC2 had met the $60 \%$ threshold. PC1 occupied a major portion of the PCA test. Within PC1, besides timber production, gross forestry value shows negative correlation to other ecosystem services as well. 
Additionally, in PC2, we found a negative correlation between water yield and grain production,

309 which was not observed in the Pearson correlation test.

\subsection{Ecosystem services bundles}

311 In the results of ecosystem services bundles, seven time intervals in 13 counties of Yan'an area were

312 considered in the calculation. Based on k-means clusters results with standardized ecosystem services

313 values, the 11 ecosystem services from one specific year and county was considered as an entity, 7

314 time intervals and 13 counties (91 in total) of the ecosystem services group were categorized into 5

315 clusters of ecosystem service bundles. In Figure 5, the specific components of five ecosystem service

316 bundles are displayed. For each bundle, the dominant ecosystem services were used to name the

317 bundles. The five bundles are identified as food production, sediment retention, forest habitat,

318 landscape value and timber production. These five ecosystem service bundles indicate the value

319 distribution of 11 ecosystem services specifically at county-level and in a certain research year.

320 According to the value of ecosystem services in each bundle, bundle 1 Food production was

321 dominated by provisioning services, led by fruit production, followed by grain and livestock

322 production. Bundle 2 Sediment retention had the highest sediment retention value while the

323 remaining 10 ecosystem services were fluctuated amongst each other. Carbon sequestration, habitat

324 quality and outdoor recreation were the focal ecosystem services in bundle 3. The cultural services

325 aesthetic landscape value and learning and inspiration were well represented in bundle 4 labeled as

326 landscape value. Bundle 5 was led by timber production, followed by water yield and grain 327 production.

328 In Figure 6 the spatial and temporal distribution of the five ecosystem service bundles in 13 counties 329 across 7 time intervals is displayed. In general, we can observe a change of overall color from 1990 to

330 2018: in 1990 the dominant color was yellow while in 2010 this color turned to be red and changed to 331 green in 2018 eventually. These color changes indicate that the dominant ecosystem service bundles 332 of Yan'an area altered from Timber Production to Sediment Retention from 1990 to 2010, and moved 333 towards Landscape Value in 2018. Starting from 1990, in the Northern part of Yan'an area, Timber 334 production was the major ecosystem service bundle. In 1995, the distribution of the ecosystem service 335 bundles almost remained the same. However, from 2000 we observe a transformation from Timber 336 production to Sediment retention in Wuqi, Baota and Yichuan, and to Landscape value in Zhidan 337 county. The distribution of ecosystem service bundles remained the same in the years 2005 and 2010, 338 but starting in 2015 there are 7 Landscape value bundles covering the Yan'an area. Luochuan was the 339 only remaining county with a Food production bundle, while Huangling and Huanlong kept a 
340 Habitat quality bundle during the whole research period. A summary of changes in ecosystem service

341 bundles numbers can be found in Table 2 .

\section{Discussion}

343 Eleven ecosystem services in Yan'an area were quantified and their spatial and temporal changes

344 were estimated. The trade-offs and synergies between these ESs were analysed, and ecosystem

345 service bundles were assessed. Base on the results, we observed increases in the majority of the 346 ecosystem services from 1990 to 2018, and particularly dramatic increases of fruit production, habitat 347 quality, carbon sequestration, learning and inspiration and outdoor recreation that occurred since 348 2000. Correlation analysis revealed relations between specific ecosystem services, both trade-offs and 349 synergies were observed. Synergies were found between sediment retention, carbon sequestration, 350 outdoor recreation, fruit production, habitat quality, learning and inspiration, livestock production 351 and aesthetic value of landscape, while a trade-off was found between timber production and water 352 yield. The ecosystem services bundles results showed an obvious change since 2000, as the majority 353 of the ecosystem bundles changed from timber production to landscape value.

354 The results of ES quantification were similar to previous studies on the Loess Plateau, and confirm 355 that there were increasing trends of sediment retention and carbon sequestration during the 356 implementation of the GGP (Yang et al. 2018). In the results of sediment retention and carbon 357 sequestration in Figure 2, we observe a drop from 1990 to 1995. This indicates an ordinary trend in 358 the Yan'an area before restoration implementation, representing a general degradation trend on the 359 Loess Plateau. Shortly after the implementation of the GGP started and since 2000 both of these 360 regulating services slightly increased. From the collected 4 carbon input indices (carbon in above361 ground biomass, below-ground biomass, litter biomass and carbon in soil), we observe huge 362 differences in aboveground and below ground biomass between cropland and forest: forest contains 36310 times higher biomass values than cropland on the Loess Plateau (Xiao et al. 2016; Feng et al. 2017). 364 Due to the traditional practice of removing crop residues after harvest, in the Carbon model the 365 carbon content of the litter layer of cropland was set at 0 . Hence the introduction of the GGP, through 366 an increase of forest and reduction of cropland, has increased the local carbon storage of the Yan'an 367 area. We observed a dramatic drop of water yield in 1995, and the value kept being consistently low 368 compared to 1990 until the end of the assessment period in 2018. According to the observational 369 evidence from many regions in the world, land use and climate change are recognized to be two 370 majors drivers affecting baseflow (Price 2011). On the Chinese Loess Plateau, the newly planted forest 371 and grassland have caused an increase of both evapotranspiration and net primary productivity 372 (Feng et al. 2016). Additionally, in recent decades a significant increase of extreme warm surface 
373 temperature and a decrease of average daily precipitation were observed on the Chinese Loess 374 Plateau (Sun et al. 2016). Wang et al. (2015) initiated a research of human activity impacts on runoff 375 and sediment transportation in Yan river, which is the main river in the Yan'an area, and concluded 376 that human activity is a main reason caused runoff decline by changing the land cover. Meanwhile, 377 according to the algorithm of Seasonal water yield model, precipitation, temperature and potential 378 evapotranspiration are the main input indicators which affecting the results of water yield, decline 379 of precipitation and increase of temperature and evapotranspiration could be a main reason to cause 380 water yield decrease. HBQ increased around 7\% from 2000 to 2010 and showed a slight decreasing 381 trend between 2010 to 2018. Habitat quality from the InVEST model is calculated based on distance 382 and the area of disturbances from the habitat, as well as sensitivity of land cover type to threats. In 383 comparison, forest is less sensitive to threats than cropland and grassland (Nelson et al. 2018). From 384 the land use change table in supplementary Table A6 we found that the urban area expanded more 385 than two times by 2018 compared to 1990, while forest land continually increased from 1995 to 2010 386 and maintained almost the same value after 2010. This trend could be explained as land restoration 387 leading to an expansion of forest area and increase of HBQ from 2000 to 2010; after 2010, reforestation 388 stagnated while urban area expansion caused a slight decrease of HBQ.

389 Cultural services often related to spiritual significance and landscape aesthetics (Daniel et al. 2012). 390 It's hard to quantify and monitor the cultural services especially when crossing a huge time span, 391 due to the difficulties of understanding human emotions from the past. However, in this study, 392 despite of data deficiency of cultural services, we quantified the amount and monitored the dynamics 393 of cultural services in terms of outdoor recreation, aesthetic landscape value and learning and 394 inspiration on the Loess Plateau. In previous publications researching ecosystem services' dynamics 395 on the Loess Plateau region, cultural services were frequently neglected (Q. Feng et al. 2017; Yang et 396 al. 2018). Only a few studies have investigated dynamics of cultural services during the 397 implementation of GGP. Hou et al. (2017) only recorded a slight increase of recreation capacity from 3982000 till 2010 in Baota distinct in Yan'an area. Similar results of outdoor recreation have been found 399 in our study while, additionally, a decrease in 1995 had been observed. Tourism is one essential 400 indicator of cultural services indicating the attractiveness of a landscape, which has been studied by 401 many ecosystem researches (Raudsepp-Hearne et al. 2010; Remme et al. 2015). In this study, there is 402 insufficient tourism data when tracing back to 1990; however, it is believed that in Yan'an area 403 tourism coincides with outdoor recreation. According to the tourist numbers in the recent five years, 404 Huanglong and Huangling county received the most tourists among other counties and has the 405 highest forest cover, while outdoor recreation is indicating the forest cover rate. An increase of 406 aesthetic landscape value was observed from 1990 till 2018 indicating an expansion of terrace area. 
407 Terraces not only brings unique scenery to the local landscape, but also stimulate crop yield. A field 408 experiment on the Loess Plateau found that the yield of a 3-year-old terraced land was $27 \%$ higher 409 than slope farmlands (X. Liu et al. 2011). Based on the dramatic increase of learning and inspiration 410 value from 1990 to 2015, we can speculate local people had paid more attention to their indigenous 411 cultural learning and entertainment.

412 Results of ecosystem service bundles displayed the temporal and spatial dynamics of ecosystem 413 services before and after GGP implementation. From Figure 6, it can be observed that starting from 4142000 , there was a transformation of ecosystem service bundles from Timber production to Sediment 415 retention and landscape value in northern Yan'an (particularly in Wuqi, Zhidan, Ansai, Baota, 416 Zichang, Guanquan and Yanchang counties). After 2015, since GGP policy in Yan'an area had altered 417 from mainly reforesting land to maintain the reforested land, change of land use types was 418 minimized. From the results of ecosystemt service bundles map, we discovered the general process 419 of ecosystem services components change by land restoration in the Loess Plateau. In the start 10 420 years of GGP from 2000 to 2010, there was an increase of regulating services at expense of 421 provisioning services. Following by the cultural services surpassing regulating services and occupied majority of the ecosystem services bundles. While during 2010 till 2018, base on Figure 2, regulating services was not decreasing, it was the propotion of cultural services in ecosystem services bundle increased. Meanwhile we observe that the ecosystem service bundles became stable after 2015 since there was no ecosystem service bundles change between 2015 and 2018.

According to the land use change map from Figure A7, it can be observed that the majority of the land use change occurred in the northern part of Yan' an while Huanglong and Huangling counties 428 feature much less land use changes. During the GGP implementation, there was a decrease in cultivated land and an increase in grassland and forest area in return (Figure A7 and Table A6). 430 Therefore, it could be expected that grain production would be reduced due to the shrinkage of 431 cropland. However, according to the results in Figure 3 there was an increase of average grain 432 production from 2000 to 2010 . One explanation is that there has been an increase of grain productivity 433 due to the improvement of agricultural technology as well as the terrace expansion; for instance, there 434 has been an increased utilization of fertilizer on the Loess Plateau (Fan et al. 2005), and from 2000 till 435 2008, grain yields increased from $3000 \mathrm{t} / \mathrm{ha}$ to $3900 \mathrm{t} / \mathrm{ha}$ on the Chinese Loess Plateau (Lü et al. 2012).

436 Change of economic factors in terms of gross agricultural value (GAV), gross industrial value (GIV) 437 and gross forestry value (GFV) as well as population density (POD) were also included in the STI test 438 (Fig A8). Timber production plummeted after 1995 and was almost 5 times lower in 2005. This change may due to the introduction of GGP policy that banned all tree felling activities, thereupon triggering 
440 a decrease of GFV from 1990 to 2005. Meanwhile, the fruit industry has blossomed from 2000 in parts 441 of Yan'an area, especially in Luochuan county, which is famous for its high quality and quantity of 442 apple production (Ma et al. 2015). Additionally, according to the GGP strategy there were two types 443 of forests restored from cropland and bare land: economic forest and ecological forest. Economic 444 forest contains various species of fruit trees, nut trees and paper trees which support local farmers' 445 income, for instance, apple, pear, red dates and walnuts, whereas for ecological forest restoration 446 usually drought-enduring trees and shrubs are selected, such as Robinia pseudoacacia, Hippophae 447 rhamnoides and Platycladus orientalis (Deng et al. 2014). Therefore, an increasing area of restored 448 economic forest expanded the fruit tree area simultaneously and improved fruit production as a 449 result.

450 To sum up, implementation of the Chinese land restoration project GGP not only improved the 451 majority of ecosystem services on the Chinese Loess Plateau, but also lead to local economic growth 452 through subsidies and agricultural products. Results of this study are coherent with the " 4 returns 453 approach", since landscape restoration is expected to enhance and restore ecosystem functions which 454 leads to improved delivery of ecosystem services and the returns of natural capital, social capital, 455 financial capital and the return of inspiration (Moolenaar 2016). According to the guidelines of the 456 ESP (Ecosystem Services Partnership), impact assessment and integrated cost-benefit analysis of land 457 restoration are essential procedures to achieve sustainable landscape management and support land 458 use planning (Groot et al. 2018). For instance, Groot et al. (2020) undertook an integrated cost-benenfit 459 analysis of large-scale landscape restoration in Spain. It is therefore suggested to apply an integrated 460 cost-benefit analysis to GGP to unravel the social-economical and environmental impacts of land 461 restoration on the Chinese Loess Plateau in a structured and coherent way.

462 This research covered an area of $37,000 \mathrm{~km}^{2}$ and considered an assessment period of almost 30 years. 463 Therefore, there are many factors that could change ecosystem services, for instance, population 464 increase, urban expansion, climate change, etc. However, according to the discussion above, the GGP 465 is understood as a major driver that changed the land cover and ecosystem services simultaneously. 466 Overall, the GGP implementation has had positive impacts on enhancing a majority of provisioning, 467 regulating and cultural services, while the GGP shows negative impacts on timber production and 468 water yield. Decrease of timber production was mainly due to land management policy but may not 469 be a severe issue, as it could be managed by timber import from other provinces. Another concern is 470 the decrease of water yield, although due to the shrinkage of cropland area by GGP project, the 471 demand for agricultural water use had decreased at the same time. Liang et al. (2018) reported a 472 decline of soil moisture after GGP imeplementation, forest has lower moisture content among 473 cropland and grassland, while revegetation on the Loess Plateau is considered as a main driver for 
the moisture decrease. Clearly, forest expansion had brought more pressure on water supply than grassland on the Loess Plateau with an average annual precipitation from $250 \mathrm{~mm} \sim 600 \mathrm{~mm}$. In order to maintain local water supply, it is recommended that further landscape restoration plans balance the revegetation area of forest and grassland.

\section{Conclusion}

479 In this study, the dynamics of 11 ecosystem services in 13 counties from Yan'an area were quantified 480 within a time range from 1990 to 2018. An increasing trend was found in the majority of the 481 provisioning, regulating and cultural services including fruit production, livestock production, 482 sediment retention, carbon sequestration, habitat quality, aesthetic landscape value, learning and 483 inspiration and outdoor recreation while seasonal water yield and timber production showed 484 decreasing trends. We observed synergies between regulating and cultural services, including SDR, 485 CAS, HBQ and OR, while both trade-offs and synergies were found in provisioning services. TBP 486 was negatively correlated with CAS, SDR, OR, HBQ and LAI whereas GAP showed synergies. 487 Ecosystem service bundles revealed temporal differences from 2000 until 2015 as well as spatial 488 differences between northern and southern Yan'an. The process of ecosystem services components 489 change by GGP was discovered, to start with increasing regulating services at expense of provisioning services, followed by cultural services exceeding regulating services and occupied the main proportion. Implementation of the GGP is recognized as a key factor changing the land use and affecting ecosystem service bundles. To conclude, GGP implementation had improved the majority of regulating and cultural services whereas it constrained timber production and local water yields. This study reveals the dynamics of ecosystem services while land restoration occurred; this knowledge supports future land use planning and helps to maintain a balance between different ecosystem services. From this study, it is suggested for the Yan'an government to pay attention to local timber products balance, as well as balancing forest and grassland area to maintain sustainable water supply.

Acknowledgments: This research was partially funded by Commonland Foundation; and the

500 Chinese Scholarship Council [grant number 201807720055].

\section{Declaration of Competing Interest}

502 The authors declare that they have no known competing financial interests or personal relationships that could have appeared to influence the work reported in this paper. 


\section{References}

Allan, J.D., P.B. McIntyre, S.D.P. Smith, B.S. Halpern, G.L. Boyer, A. Buchsbaum, G.A. Burton, et al. 2013. “Joint Analysis of Stressors and Ecosystem Services to Enhance Restoration Effectiveness." Proceedings of the National Academy of Sciences of the United States of America 110 (1): 372-77. https://doi.org/10.1073/pnas.1213841110.

Benayas, Rey José M, Adrian C Newton, Anita Diaz, and James M Bullock. 2009. “Enhancement of Biodiversity and Ecosystem Services by Ecological Restoration: A Meta-Analysis." Science (New York, N.Y.) 325 (5944): 1121-24. https://doi.org/10.1126/science.1172460.

Bennett, Elena M, and Patricia Balvanera. 2007. "The Future of Production Systems in a Globalized World." Frontiers in Ecology and the Environment 5 (4): 191-98.

Bennett, Elena M, Garry D Peterson, and Line J Gordon. 2009. “Understanding Relationships among Multiple Ecosystem Services." Ecology Letters 12 (12): 1394-1404.

Bhattarai, Rabin, and Dushmata Dutta. 2007. “Estimation of Soil Erosion and Sediment Yield Using GIS at Catchment Scale." Water Resources Management 21 (10): 1635-47.

Chen, Hao, Luuk Fleskens, Jantiene Baartman, Fei Wang, Simon Moolenaar, and Coen Ritsema. 2020. “Impacts of Land Use Change and Climatic Effects on Streamflow in the Chinese Loess Plateau: A Meta-Analysis." Science of the Total Environment 703: 134989. https://doi.org/10.1016/j.scitotenv.2019.134989.

Chen, Yiping, Kaibo Wang, Yishan Lin, Weiyu Shi, Yi Song, and Xinhua He. 2015. “Balancing Green and Grain Trade." Nature Geosci 8 (10): 739-41. https://doi.org/10.1038/ngeo2544.

Costanza, R, R D’arge, De Groot, Farber R., Grasso S., Hannon M., Naeem B., et al. 1997. “A. The Value of the World's Ecosystem Services and Natural Capital." Nature 387 (6630): 253-60. http://dx.doi.org/10.1038/387253a0.

Daniel, Terry C, Andreas Muhar, Arne Arnberger, Olivier Aznar, James W Boyd, Kai M A Chan, Robert Costanza, Thomas Elmqvist, Courtney G Flint, and Paul H Gobster. 2012. “Contributions of Cultural 

19.

Deng, Lei, Dong-Gill Kim, Miaoyu Li, Chunbo Huang, Qiuyu Liu, Min Cheng, Zhouping Shangguan, and Changhui Peng. 2019. “Land-Use Changes Driven by ‘Grain for Green’ Program Reduced Carbon Loss Induced by Soil Erosion on the Loess Plateau of China." Global and Planetary Change 177: 101-15.

Deng, Lei, Guo-bin Liu, and Zhou-ping Shangguan. 2014. “Land-use Conversion and Changing Soil Carbon Stocks in C Hina's ‘Grain-for-Green’Program: A Synthesis.” Global Change Biology 20 (11): 3544-56.

Fan, Tinglu, B A Stewart, Wang Yong, Luo Junjie, and Zhou Guangye. 2005. “Long-Term Fertilization Effects on Grain Yield, Water-Use Efficiency and Soil Fertility in the Dryland of Loess Plateau in China."

Feng, Qiang, Wenwu Zhao, Bojie Fu, Jingyi Ding, and Shuai Wang. 2017. “Ecosystem Service Trade-Offs and Their Influencing Factors: A Case Study in the Loess Plateau of China." Science of The Total Environment

Feng, Xiaoming, Bojie Fu, Shilong Piao, Shuai Wang, Philippe Ciais, Zhenzhong Zeng, Yihe Lü, et al. 2016.

Forbes, Valery E, and Nika Galic. 2016. “Next-Generation Ecological Risk Assessment: Predicting Risk from Molecular Initiation to Ecosystem Service Delivery." Environment International 91: 215-19.

Fu, B. J., W. W. Zhao, L. D. Chen, Q. J. Zhang, Y. H. Lü, H. Gulinck, and J. Poesen. 2005. “Assessment of Soil https://doi.org/https://doi.org/10.1016/j.envint.2016.03.002. Flows Create Ecological Surprises." Trends in Ecology \& Evolution 23 (4): 211-19. 
554 Groot, Dolf de, Robert Costanza, Dieter Van den Broeck, and James Aronson. 2011. “A Global Partnership for Ecosystem Services." Solutions: For A Sustainable \& Desirable Future.

Groot, Dolf de, Simon Moolenaar, and Martine Van Weelden. 2018. “Guidelines for Integrated Ecosystem Services Assessment." Ecosystem Services Partnership 09. https://www.es-partnership.org/esp-guidelines/.

Groot, Rudolf de, Simon W Moolenaar, Joris de Vente, Vicent De Leijster, Maria Eugenia Ramos, Ana Belen Robles, Yanniek Schoonhoven, and Pita Verweij. 2020. “Integrated Cost-Benefit Analysis of Large Scale Landscape Restoration: Comparing Almond Monoculture with Multi-Functional Sustainable Land Use in SE Spain." Submitted to Ecosystem Services.

Guo, Jing, and Peng Gong. 2016. “Forest Cover Dynamics from Landsat Time-Series Data over Yan'an City on the Loess Plateau during the Grain for Green Project." International Journal of Remote Sensing 37 (17): 4101-18.

Hall, Linnea S, Paul R Krausman, and Michael L Morrison. 1997. “The Habitat Concept and a Plea for Standard Terminology." Wildlife Society Bulletin, 173-82.

Hector, Andy, and Robert Bagchi. 2007. “Biodiversity and Ecosystem Multifunctionality.” Nature 448 (7150): 188-90.

Hou, Ying, Yihe Lü, Weiping Chen, and Bojie Fu. 2017. “Temporal Variation and Spatial Scale Dependency of Ecosystem Service Interactions: A Case Study on the Central Loess Plateau of China." Landscape Ecology 32 (6): 1201-17.

Legendre, Pierre, Miquel De Cáceres, and Daniel Borcard. 2010. “Community Surveys through Space and Time: Testing the Space-Time Interaction in the Absence of Replication." Ecology 91 (1): 262-72. https://doi.org/10.1890/09-0199.1.

Li, Ting, Yihe Lü, Bojie Fu, Weiyin Hu, and Alexis J. Comber. 2019. “Bundling Ecosystem Services for Detecting Their Interactions Driven by Large-Scale Vegetation Restoration: Enhanced Services While Depressed Synergies." Ecological Indicators 99 (April): 332-42. https://doi.org/10.1016/j.ecolind.2018.12.041. 
Liang, Haibin, Yayong Xue, Zongshan Li, Shuai Wang, Xing Wu, Guangyao Gao, Guohua Liu, and Bojie Fu. 2018. “Soil Moisture Decline Following the Plantation of Robinia Pseudoacacia Forests: Evidence from the Loess Plateau." Forest Ecology and Management 412: 62-69.

Liu, Xiuhua, Baolin He, Zaoxia Li, Jianglin Zhang, Ling Wang, and Zhi Wang. 2011. “Influence of Land Terracing on Agricultural and Ecological Environment in the Loess Plateau Regions of China." Environmental Earth Sciences 62 (4): 797-807.

Liu, Yuanxin, Yihe Lü, Bojie Fu, Paul Harris, and Lianhai Wu. 2019. “Quantifying the Spatio-Temporal Drivers of Planned Vegetation Restoration on Ecosystem Services at a Regional Scale." Science of The Total Environment 650: 1029-40.

Ljung, Karin, Fiona Maley, Angus Cook, and Philip Weinstein. 2009. “Acid Sulfate Soils and Human Health A Millennium Ecosystem Assessment." Environment International 35 (8): 1234-42. https://doi.org/https://doi.org/10.1016/j.envint.2009.07.002.

Lü, Yihe, Bojie Fu, Xiaoming Feng, Yuan Zeng, Yu Liu, Ruiying Chang, Ge Sun, and Bingfang Wu. 2012. “A Policy-Driven Large Scale Ecological Restoration: Quantifying Ecosystem Services Changes in the Loess Plateau of China." PLoS ONE 7 (2): 1-10. https://doi.org/10.1371/journal.pone.0031782.

Ma, Y J, J J Zhao, Hong Deng, Yonghong MENG, and Yurong GUO. 2015. “Construction of Comprehensive Quality Evaluation and Grading System for Fresh Fuji Apple in Luochuan, Shaanxi." Food Science 36 (1): $69-74$.

MEA. 2005. Ecosystems and Human Well-Being: Wetlands and Water. World Resources Institute.

Moolenaar, Simon W. 2016. “Four Returns: A Long-Term Holistic Framework for Integrated Landscape Management and Restoration Involving Business." Solutions Journal, no. October: 36-41.

Nelson, Erik, Driss Ennaanay, Stacie Wolny, Nasser Olwero, Kari Vigerstol, Derric Penning-ton, Guillermo Mendoza, et al. 2018. “InVEST 3.6.0 User's Guide. The Natural Capital Project.” 
602

603

604

605

606

607

608

609

610

611

612

613

614

615

616

617

618

619

620

621

622

623

Peng, Jian, Xiaoxu Hu, Xiaoyu Wang, Jeroen Meersmans, Yanxu Liu, and Sijing Qiu. 2019. “Simulating the Impact of Grain-for-Green Programme on Ecosystem Services Trade-Offs in Northwestern Yunnan, China." Ecosystem Services 39 (October): 100998. https://doi.org/10.1016/j.ecoser.2019.100998.

Persson, Martin, Jesper Moberg, Madelene Ostwald, and Jintao Xu. 2013. “The Chinese Grain for Green Programme: Assessing the Carbon Sequestered via Land Reform." Journal of Environmental Management 126 (September): 142-46. https://doi.org/https://doi.org/10.1016/j.jenvman.2013.02.045.

Power, Alison G. 2010. “Ecosystem Services and Agriculture: Tradeoffs and Synergies.” Philosophical Transactions of the Royal Society B: Biological Sciences 365 (1554): 2959-71. https://doi.org/10.1098/rstb.2010.0143.

Price, Katie. 2011. “Effects of Watershed Topography, Soils, Land Use, and Climate on Baseflow Hydrology in Humid Regions: A Review." Progress in Physical Geography 35 (4): 465-92.

Raudsepp-Hearne, C., G. D. Peterson, and E. M. Bennett. 2010. “Ecosystem Service Bundles for Analyzing Tradeoffs in Diverse Landscapes." Proceedings of the National Academy of Sciences 107 (11): 5242-47. https://doi.org/10.1073/pnas.0907284107.

Remme, Roy P., Bram Edens, Matthias Schröter, and Lars Hein. 2015. “Monetary Accounting of Ecosystem Services: A Test Case for Limburg Province, the Netherlands." Ecological Economics 112 (April): 116-28. https://doi.org/10.1016/j.ecolecon.2015.02.015.

Renard, Delphine, Jeanine M. Rhemtulla, and Elena M. Bennett. 2015. “Historical Dynamics in Ecosystem Service Bundles." Proceedings of the National Academy of Sciences 112 (43): 13411-16. https://doi.org/10.1073/pnas.1502565112.

Renard, Kenneth G. 1997. "Predicting Soil Erosion by Water: A Guide to Conservation Planning with the Revised Universal Soil Loss Equation (RUSLE)."

Sun, Wenyi, Xingmin Mu, Xiaoyan Song, Dan Wu, Aifang Cheng, and Bing Qiu. 2016. “Changes in Extreme Temperature and Precipitation Events in the Loess Plateau (China) during 1960-2013 under Global Warming." Atmospheric Research 168: 33-48. 
Sun, Wenyi, Quanqin Shao, Jiyuan Liu, and Jun Zhai. 2014. “Assessing the Effects of Land Use and Topography on Soil Erosion on the Loess Plateau in China." CATENA 121 (Supplement C): 151-63. https://doi.org/https://doi.org/10.1016/j.catena.2014.05.009.

Tolessa, Terefe, Feyera Senbeta, and Moges Kidane. 2017. “The Impact of Land Use/Land Cover Change on Ecosystem Services in the Central Highlands of Ethiopia." Ecosystem Services 23: 47-54.

Wang, Fei, Rudi Hessel, Xingmin Mu, Jerry Maroulis, Guangju Zhao, Violette Geissen, and Coen Ritsema. 2015. “Distinguishing the Impacts of Human Activities and Climate Variability on Runoff and Sediment Load Change Based on Paired Periods with Similar Weather Conditions: A Case in the Yan River, China." Journal of Hydrology 527: 884-93. https://doi.org/https://doi.org/10.1016/j.jhydrol.2015.05.037.

Wold, Svante, Kim Esbensen, and Paul Geladi. 1987. "Principal Component Analysis.” Chemometrics and Intelligent Laboratory Systems 2 (1-3): 37-52.

Xiao, lie, Guobin Liu, Sha Xue, and Zhang.Chao. 2016. “Effects of Land Use Types on Soil Water and Aboveground Biomass in Loess Hilly Region." Bulletin of Soil and Water Conservation 36 (4).

Xu, Xin, Daojun Zhang, Yu Zhang, Shunbo Yao, and Jinting Zhang. 2020. “Evaluating the Vegetation Restoration Potential Achievement of Ecological Projects: A Case Study of Yan'an, China." Land Use Policy 90 (January). https://doi.org/10.1016/j.landusepol.2019.104293.

Yang, Siqi, Wenwu Zhao, Yanxu Liu, Shuai Wang, Jing Wang, and Ruijie Zhai. 2018. “Influence of Land Use Change on the Ecosystem Service Trade-Offs in the Ecological Restoration Area: Dynamics and Scenarios in the Yanhe Watershed, China." Science of the Total Environment 644 (19): 556-66. https://doi.org/10.1016/j.scitotenv.2018.06.348.

Yaofeng, Luo, and Liu Jinlong. 2013. “Study on the Cypress Culture and Protection in the Mausoleum of Yellow Emperor in Shaanxi Province." Cover Photos Credits, 37.

Zhang, Wei, Peng Li, Lie Xiao, Binhua Zhao, and Peng Shi. 2019. “Impacts of Slope and Land Use Types on the Soil Organic Carbon in the Loess Hilly Plateau." Acta Pedologica Sinica. https://doi.org/10.11766/trxb201901220367. 
652 Zhang, Yi, Youke Wang, Qinxiao Wu, and Guo-bin Liu. 2001. “Comparision of Litterfall and Its Process

653 between Some Forest Types in Loess Plateau." Journal of Soil and Water Conservation 15 (5).

654 https://doi.org/DOI : 10. 13870 /jcnki st bcxb. 2001. s1. 025.

655 


\section{Figures}

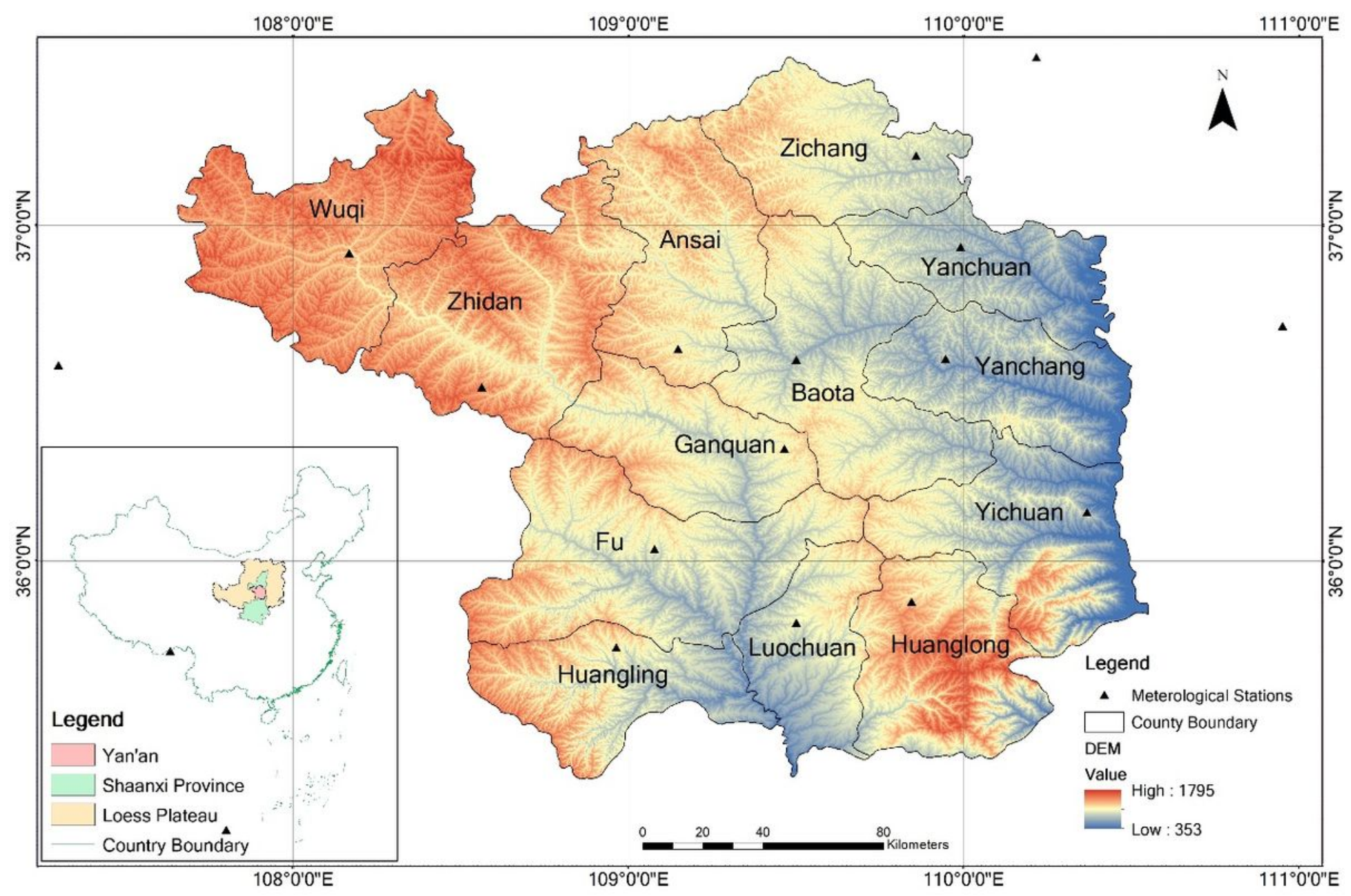

\section{Figure 1}

Location of the study area Yan'an including county boundary, meteorological stations and elevation. Note: The designations employed and the presentation of the material on this map do not imply the expression of any opinion whatsoever on the part of Research Square concerning the legal status of any country, territory, city or area or of its authorities, or concerning the delimitation of its frontiers or boundaries. This map has been provided by the authors. 

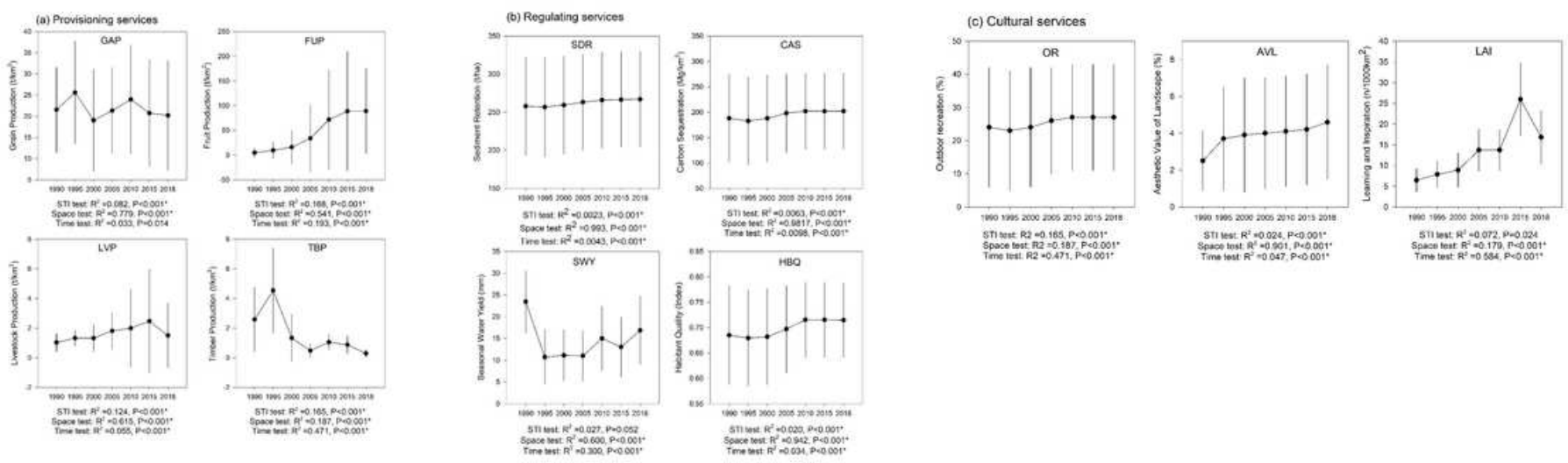

Figure 2

Space and Time Interaction (STI) test results for 11 ecosystem services across the 13 counties in Yan'an from 1990 to 2018. Note: error bars indicate standard deviation were calculated based on the average value of ecosystem services from 13 counties in one specific year. GAP: grain production; FUP: fruit production; LVP: livestock production; TBP: Timber production; SDR: sediment retention; CAS: carbon sequestration; HBQ: habitat quality; SWY: seasonal water yield; OR: outdoor recreation; AVL: aesthetic landscape value; LAl: learning and inspiration.

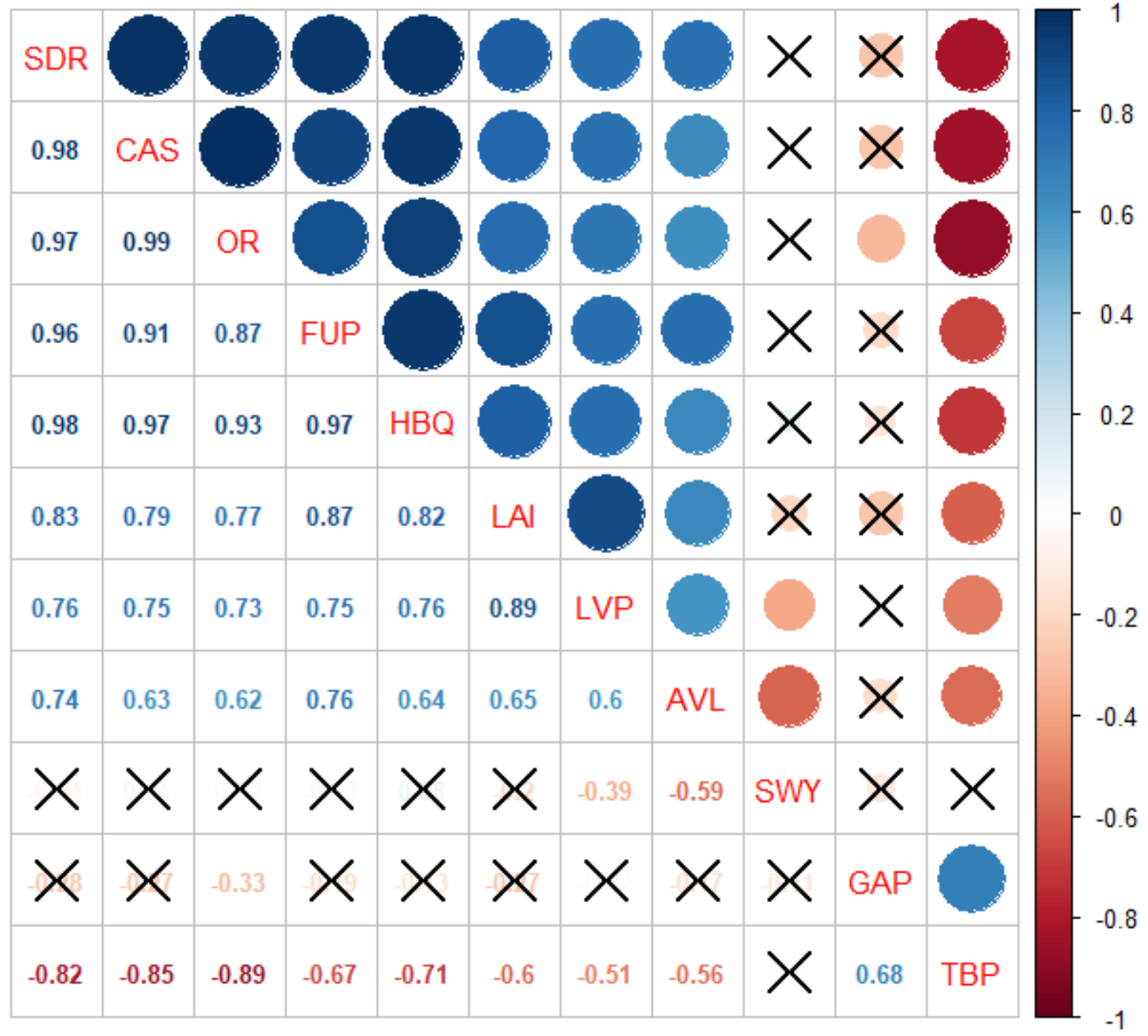


Figure 3

Correlations between different ecosystem services. Numbers illustrate the Pearson correlation coefficient (r) of linear correlations. Blue dots indicate a synergy, while red dots indicate a trade-off. The color depth indicates the strength of the correlation. Crosses indicate an insignificant result $(p>0.05)$. Abbreviations can be found in Figure 2.

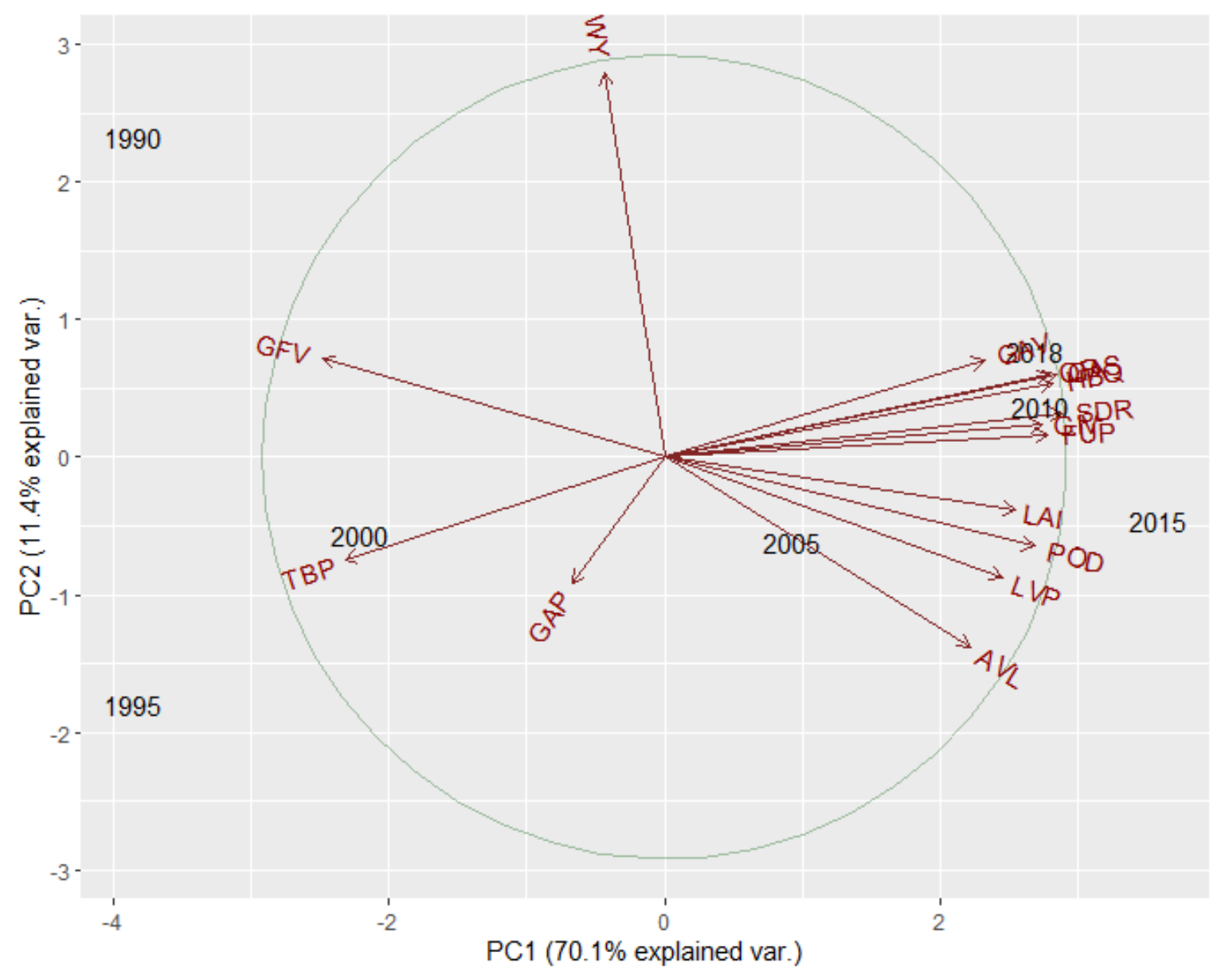

\section{Figure 4}

Principle Component Analysis of ecosystem services. 

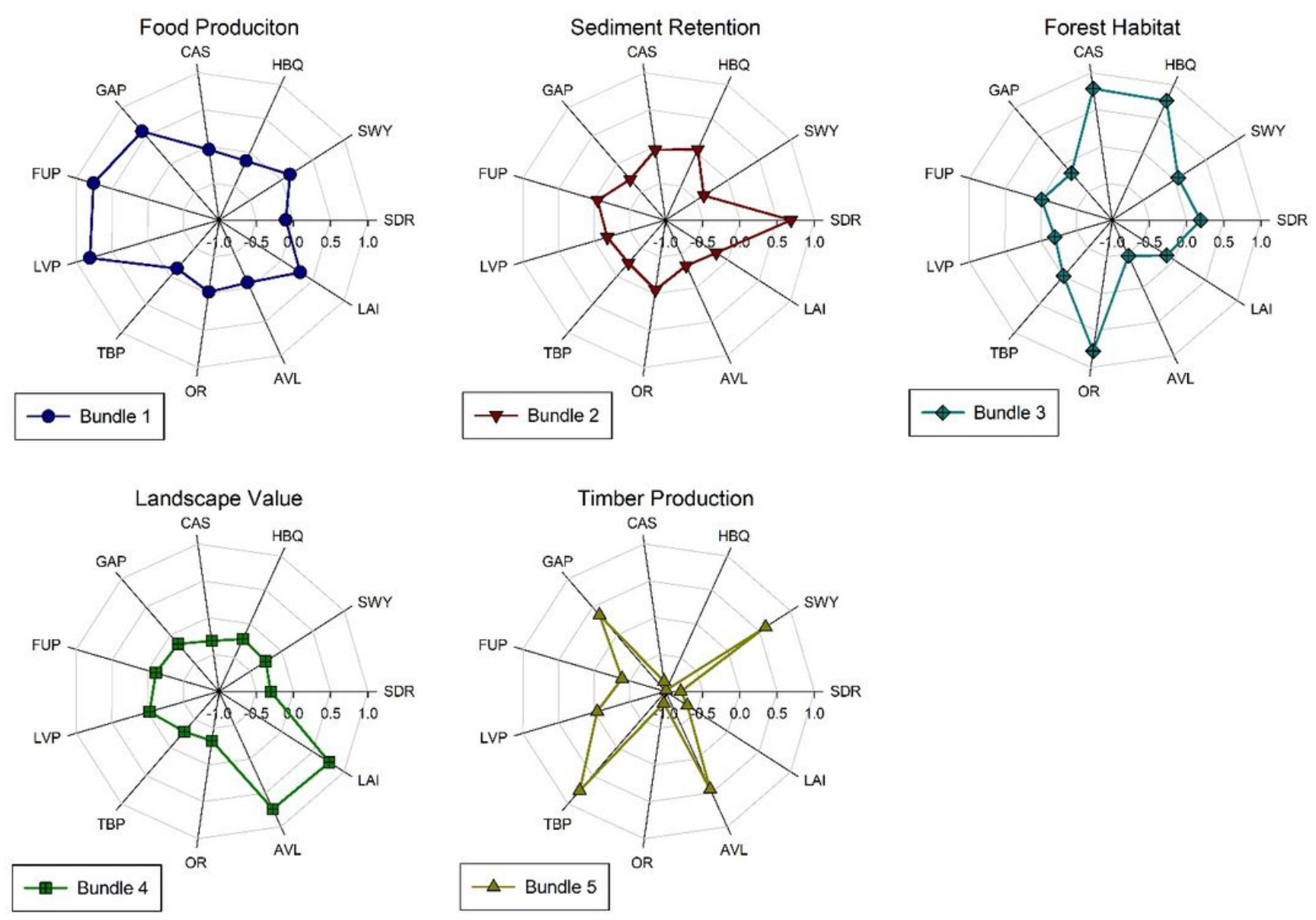

\section{Figure 5}

Ecosystem service bundles. Note: 1. Food production, 2. Sediment retention, 3. Forest and Habitat, 4. Landscape value, 5. Timber production. 

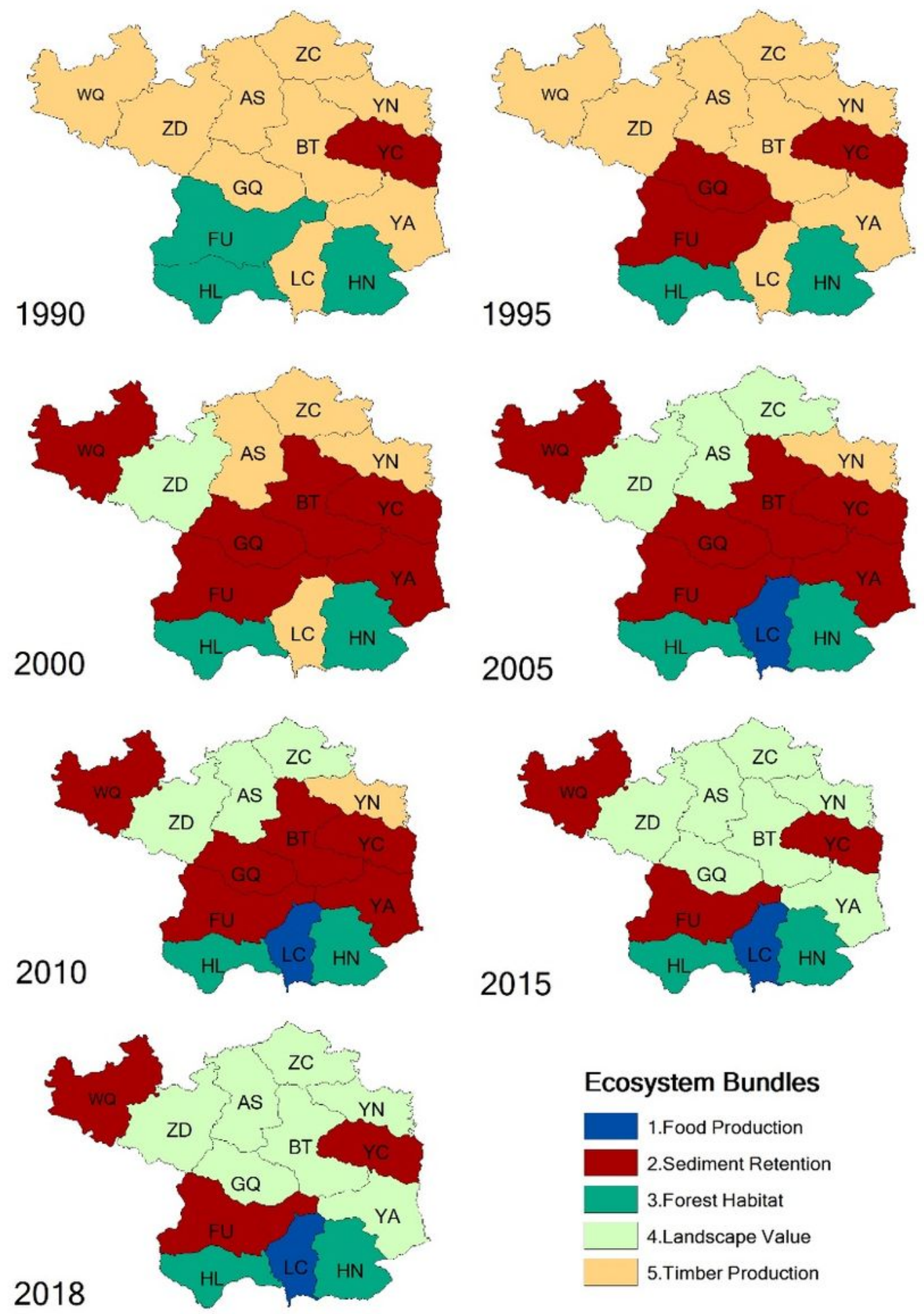

Figure 6

Spatial and temporal distribution of five ecosystem service bundles in Yan'an area. Note: WQ: Wuqing; ZD: Zhidan; AS: Ansai; ZC: Zichang; YN: Yanchuan; YC:Yanchang; BT: Baota; GQ: Ganquan; YA: Yichuan; HL: Huangling; LC: Luochuan; HN: Huanglong. Note: The designations employed and the presentation of the material on this map do not imply the expression of any opinion whatsoever on the part of Research 
Square concerning the legal status of any country, territory, city or area or of its authorities, or concerning the delimitation of its frontiers or boundaries. This map has been provided by the authors.

\section{Supplementary Files}

This is a list of supplementary files associated with this preprint. Click to download.

- Supplementary.docx 